\title{
DESVENDANDO AS FACES DA AMAMENTAÇÃO ATRAVÉS DA PESQUISA QUALITATIVA
}

\author{
REVEALING DIFFERENT ASPECTS OF BREASTFEEDING THROUGH \\ QUALITATIVE RESEARCH \\ PARA DESVELAR LAS FACETAS DE LA AMAMANTACIÓN A TRAVÉS DE \\ LA INVESTIGACIÓN CALITATIVA.
}

Isília Aparecida Silva ${ }^{1}$

\begin{abstract}
RESUMO: Buscando compreender o cenário das questöes ligadas à prática da amamentação que têm suscitado o quadro atual e as tendências em produção científica nesta área, foram comentados os principais conceitos emergidos de estudos qualitativos realizados por enfermeiras a partir de diferentes perspectivas teóricas. Estes mostram que o processo de amamentar depende dos significados atribuidos pela mulher à experiência de amamentar, construídos através de suas histórias de vida e das interações atuais em seu ambiente familiar e comunitário. De forma individual e em seu conjunto, os trabalhos elucidam a experiência de amamentar e dão elementos para os profissionais elaborarem a sua prática na assistência à mulher, lactente e familia, nesta fase da amamentação.
\end{abstract}

PALAVRAS-CHAVE: pesquisa qualitativa, amamentação, modelo assistencial

\section{INTRODUÇÃO}

Face aos inúmeros apelos em função da saúde da criança, a prática do aleitamento materno tornou-se um instrumento básico para a solução de uma questão sanitária que muitos programas sociais e de saúde, em nível governamental, não têm dado conta de resolver - a desnutrição infantil, as doenças infecciosas e os agravos à saúde e bem estar da criança que decorrem dessas situações.

É possível compreender os impulsos que levam a sociedade a exaltar ou a ser indiferente com os rumos da prática da amamentação quando se compreende também que "a ideologia do discurso sobre o aleitamento materno depende dos papéis ocupados pela mãe e seu filho na sociedade..." (Mota, 1990, p.3). Assim, os valores sociais, relativos ao papel da mulher e da criança, vêm determinando o comportamento da sociedade, e por conseguinte, da mulher em relação à amamentação, em toda a história da civilização.

O período entre os séc. XVI e séc. XVIII, foi especialmente marcado pelo distanciamento entre mãe e filho, determinado pelo pensamento predominante sobre a criança, e a forma como esta deveria ser educada, o que foi moldando o espírito e afeto das mães, fazendo com que elas adotassem sistematicamente amas mercenárias para amamentar e cuidar de seus filhos (Donzelot, 1986; Farge; Davis, 1991).

É por volta de 1760 , que se inicia um novo discurso que pretende modificar os valores sociais vigentes em benefício das crianças, alterando a concepção sobre a infância, concedendo a elas uma atenção anteriormente não manifestada e responsabilizando a mulher na criação dos filhos, instituindo o dever da amamentação (Donzelot, 1986).

A visão histórica mostra que a sociedade re-elabora seus conceitos e representações

${ }^{1}$ Enfermeira obstétrica, Profa. Associada do Departamento de Enfermagem Materno-Infantil e Psiquiátrica da Escola de Enfermagem da USP. 
sobre um determinado fenômeno, junto ao dinamismo de seu desenvolvimento. Também assim o é com a prática da amamentação, que tem estado sob a regência da ideologia balizada pelos valores sociais, pela visão simbólica do que representa esta prática na conjunção dos papéis da mulher/mãe e da criança.

Assim, é possivel compreender os valores sociais que determinam, ainda hoje, o incentivo à amamentação a partir da visão biologiscista que reduz a mulher ao potencial da lactação $e$ obscurece o complexo social e cultural da experiência do ser em amamentação.

Esta matriz discursiva, que embute em sua essência os valores da natureza e da cultura do dever materno, não contempla a experiência da mulher em amamentar, näo autoriza o desejo materno e não atenta para as diversidades contextuais da mulher/nutriz.

As iniciativas, em favor da prática da amamentação, têm sido acompanhadas por estudos que objetivam o seguimento e avaliação dos programas instituidos. Paralelamente, com o objetivo de conhecer variáveis que poderiam estar interferindo de forma positiva ou negativa nos resultados dos programas implantados, empreendeu-se a busca de elementos que pudessem avaliar mais especificamente as atitudes maternas frente à amamentação. Na busca desses resultados, as pesquisas realizadas, em especial na década de 80 , restringiram-se na identificação de causa e efeito, abordando o comportamento materno, mais na visão epidemiológica dos diagnósticos de freqüência e duração da amamentação.

Estes estudos, embora tenham tido sua importância histórica na vigilância do movimento pró-amamentação, não responderam de fato as dúvidas e nem preencheram os vazios de conhecimento que se tinha em relação à incompreensão dos elementos decisórios que a nutriz utiliza para definir o curso da amamentação. Poderiam justificar os indices e taxas de amamentação, mas não explicavam o desenho traçado pelo desmame, na sociedade ocidental moderna.

Um dos grandes méritos da Enfermagem, nesta área, é o fato de que alguns dos trabalhos pioneiros na busca da compreensão da experiência materna em amamentar foram realizados por enfermeiras. Utilizando abordagens teóricas e metodológicas de pesquisa qualitativa, tais estudos têm propiciado o aprofundamento das questões sobre a experiência da mulher em amamentar e foram seguidos por novos estudos desenvolvidos por outros profissionais, que vêm compondo um quadro mais fiel e cada vez mais nítido, do que é a vivência da mulher, da criança e familia na experiência da amamentação.

A partir da década de 90 , observa-se a construção de um conhecimento no sentido de dar visibilidade à amamentação como uma prática social, que se dá em consonância com os determinantes que orientam os atos sociais dos individuos. Assim, sentindo a necessidade de compreender a vivência da mulher e descobrir as especificidades desta experiência, é que os profissionais têm buscado compreender a amamentação enquanto experiência vivida pela mulher.

Esse novo olhar sobre a amamentação revela que esta prática não está determinada por uma evolução biológica natural, mas é construída no cotidiano das familias, vivida pela mulher em consonância ou em conflito, em seu ambiente natural, social e cultural.

Para compreender o cenário das questões ligadas à prática da amamentação que têm suscitado o quadro atual e as tendências em produção científica nesta área, se faz necessária a compreensão e a busca das interfaces dos conceitos gerados nos estudos que vêm sendo desenvolvidos a partir da ótica da mulher, o que nos permite definir mais acuradamente o retrato da experiência de amamentar.

Com esse propósito, nos detemos nos conceitos emergidos em algumas pesquisas qualitativas que foram desenvolvidas na década de 90 , e que tiveram como objeto de estudo, revelar a experiência materna em amamentar a partir da ótica da mulher. 


\section{O DESVENDAR DO PROCESSO DA AMAMENTAÇĀO}

As pesquisas qualitativas aqui mencionadas foram desenvolvidas a partir de diferentes perspectivas metodológicas, mas em essência buscam o significado que a mulher atribui a sua experiência de amamentar, o que ela pensa, deseja , que representações ela faz sobre a experiência de amamentar.

As teses de doutorado ${ }^{\circ}$ e dissertações* ${ }^{*}$ consideradas, foram elaboradas por enfermeiras, as quais são apresentadas a seguir por autora, programa de pós-graduação oriundo e método utilizado no estudo:

ARANTES(1991) ${ }^{\circ}$, Escola de Enfermagem de Ribeirão Preto da USP, Fenomelogia

ARAÚJO $(1991)^{\circ}$, Departamento de Enfermagem da U F S C - Representação Social

SOUZA (1993)*, Escola de Enfermagem Anna Nery UFRJ, Fenomelogia

SILVA (1994)* Escola de Enfermagem da USP ${ }^{2}$, Interacionismo simbólico Social

NAKANO(1996)*, Escola de Enfermagem de Ribeirão Preto da USP, Representação

Esses estudos, originários de programas de pós-graduação de instituições de ensino de três estados da região sudeste e sul, foram desenvolvidos tendo como informantes as mulheres moradoras nas cidades de origem das autoras dos estudos ${ }^{3}$.

A pesquisa qualitativa se justifica no desenvolvimento desses estudos, uma vez que este método considera a subjetividade, na construção científica, como parte integrante do fenômeno social , na medida em que acredita-se que a realidade vai mais além dos fenômenos percebidos pelos nossos sentidos.

Assim, ao questionar o que significa para a mulher a experiência de amamentar, os estudos colocam a mulher no núcleo da ação social e toma como objetos os significados e a aproximação da subjetividade envolvida na prática de amamentar.

Estes estudos revelaram que o aleitamento materno, segundo a perspectiva da nutriz, se mostra em diferentes faces nos diversos momentos da vivência da mulher-mãe, sendo este um fenômeno existencial e não pura ou simplesmente um fenômeno biológico (Arantes, 1991; Souza, 1993; Silva, 1994).

Segundo Silva (1994), a mulher vivencia a amamentação mediante um processo de percepção, interpretação e atribuição de significados para sua experiência de amamentar, em seu ambiente natural. Os elementos utilizados para a identificação, percepção, interpretação e atribuição de significados à experiência de amamentar, constituem-se em todos os processos interativos da mulher com os sujeitos e objetos sociais em seu contexto. O conhecimento dos significados construidos nesta vivência faz com que seja compreensivel as atitudes das mães em relação a sua prática de amamentar, pois, segundo a perspectiva da interação simbólica, os seres humanos agem com base nos significados que as situações têm para eles.

Nakano (1996), ao estudar as representações de mulheres acerca da amamentação, observa que o processo de amamentar sofre as influências do ambiente doméstico e do universo feminino, em que as nutrizes realizam a prática do amamentar, observando-se a presença de múltiplas forças nesse processo, compostas, pelas representaçöes femininas e pelas interferências externas, sejam familiares ou da comunidade. Este estudo estabelece uma interface com o estudo de Silva (1994) que afirma ser a prática da amamentação definida a partir das diferentes interações sociais que a mulher estabelece em seu contexto familiar ou comunitário.

Dessa maneira é possivel compreender a amamentação como uma ação multifatorial

\footnotetext{
${ }^{2}$ Programa Interunidades de Doutoramento em Enfermagem dos campi São Paulo/Ribeirão Preto

${ }^{3}$ Ribeirão Preto, Londrina, Rio de Janeiro, São Paulo, Ribeirão Preto, respectivamente.
} 
determinada pela realidade concreta da mulher, enleada pelas representações que esta faz a partir de dados vivenciados ao longo de sua vida (Araújo, 1991).

Embora a decisão de amamentar esteja na dependência da mulher e ser, segundo Arantes (1991) uma prática que se instala e é determinada e definida no espaço privado do domínio feminino, a mulher se vê obrigada a justificar seus atos, tendo como referência o significado que suas ações e a prática da amamentação tem para ela e também para os outros envolvidos em seu contexto de vida.

Nesse sentido, Silva (1994) aponta que no evolver do processo da amamentação, a nutriz interage também com elementos determinados por uma diversidade de papéis que ela desempenha e, que estão localizados em dimensões da mulher nas mais diferentes faces da totalidade feminina, não se tratando apenas de uma mulher situada na responsabilidade de criar e nutrir aquele filho, mas de uma mulher inteira , tentando lidar com as implicações da amamentação nos seus projetos de vida profissional, pessoal, na sua sexualidade e imagem corporal . Dessa forma, a amamentação é uma das funções da mulher, que está incorporada no movimento da sua vida, junto aos demais papéis e atividades desempenhados por ela.

As representações sociais identificadas no estudo de Nakano (1996), nos leva a compreender que a amamentação é um processo feminino socialmente construído, de ideário de abnegação, doação visto por ela como ato de amor e sacrifício, tendo a mulher um papel a desempenhar, o qual de certa forma aceita e reluta em aceitar, no que a autora definiu como sendo um " movimento de acomodação e resistência". A amamentação, nesse estudo, aparece como um processo centrado nas necessidades da criança e que limita a participação de suas mães na esfera pública, pela necessidade de dedicação e proximidade do filho.

Também no estudo de Silva (1994) essa atividade é interpretada pelas mulheres como restritiva no desempenho de outras, comprometendo suas dimensões doméstica e profissional, implicando em limitação da liberdade e lazer simbolizando riscos para sua individualidade e bem estar. Dessa forma, se apresenta como uma vivência permeada por conflitos e contradiçōes, que são expressos em sentimentos ambiguos de desejo e contrariedade, face ao ideal da maternidade concebido pela sociedade.

Os estudos acima referidos, trazem, assim como no estudo de Araújo (1991), a representação da amamentação como um agente de transformaçăo e apropriação do corpo da mulher em núcleos dicotômicos de santificado /assexuado e privado/ público.

A amamentação também é percebida pelas mulheres como uma situação que provoca sentimentos ambiguos mistos de prazer e dever, resignação, que convive ao mesmo tempo com a percepção de espoliação de seu corpo e de suas emoções, de onde emergem os conflitos, muitas vezes não manifestos e não admitidos pelas mulheres, explicitados nos estudos de Arantes (1991), Araújo (1991), Silva (1994) e Nakano (1996).

$\mathrm{Na}$ sua vivência de amamentar, a mulher não se expõe ao julgamento de seus pares ou profissionais que a assistem, pois já conhece sua sentença, preferindo assim, admitir uma incapacidade em produzir o leite necessário para seu filho, ou ainda, atribuir alguma participação do recém-nascido no processo decisório. A mulher, dentro da perspectiva de ter que amamentar para demonstrar o amor pelo seu filho, passa a vivenciar conflitos quando depara com os sentimentos advindos dessa experiência (Silva ,1994).

A amamentação aparece nos discursos das mulheres nesses estudos, como representações complexas e contraditórias, em que se percebe a ambigüidade entre o prazer e a privação, amor, dor e outros sentimentos que se intercalam entre a realização e o não desejado. As opções da mulher sobre o amamentar, se dão em um universo simbólico que reflete seu contexto, seu estilo de vida e forma de inserção social e cultural.

Silva (1994) descreve o ato de amamentar como uma prática que não está centrada apenas na interação mãe-filho, mas é um processo que se expande nas demais interações da vida materna, determinado pela percepção que a mulher tem de si, do ato de amamentar e das 
implicações que este tem em sua vida, nas relações das esferas familiar e social, nas dimensões de suas emoções e de seu corpo. Esta é uma experiência que envolve a mulher em seu todo. Afeta seu físico, seus sentimentos, acarretando situações que exigem definições, tomadas de decisões, ações, implicando em reavaliação e redefinição de atitudes. Assim, as tomadas de decisão da mulher, sobre o curso da amamentação, não são causas isoladas ou fatores simplistas dependentes exclusivamente da instrumentalização desta na habilidade de manejar as técnicas de amamentação e o esvaziamento de suas mamas.

As percepções da mulher sobre o amamentar não se restringem somente ao período temporal da lactação, mas também se apresentam desde a gestação quando ela considera as possibilidades de como alimentar seu filho e se prepara assumindo posições em relação a essa situação futura. A mulher identifica mais razões para amamentar do que apenas o conhecimento que possui sobre as vantagens da amamentação, e quando decide, o faz por perceber que estas vantagens são importantes para ela e o filho (Silva,1994).

Embora, segundo Souza (1993), a mulher já trabalhe a idéia da amamentação, no seu imaginário, no decorrer da gravidez, é na situação real de amamentar o recém-nascido, que a experiência se torna concreta. Assim, ocorre o confronto entre a expectativa e a vivência real. $O$ enfrentamento de dificuldades não esperadas, dos conflitos e ambivalências, acarretam sentimentos de ansiedade e culpas nas mães-nutrizes (Silva ,1994, Nakano ,1996).

A prática da amamentação estabelece uma interação básica entre mãe e filho, que implica na percepção de efeitos da linguagem corporal da criança sobre a mãe. Desde o princípio a mãe passa por um processo de aprendizado para conhecer e compreender a linguagem do recém-nascido. As manifestações de comportamento deste têm grande impacto sobre a forma como a mãe constrói o significado da experiência de amamentar e como ela se vê praticando a amamentação. É através da interpretação dada a essas manifestações que a mãe se percebe segura ou insegura, quanto à sua capacidade de garantir a alimentação da criança (Silva , 1994).

Concomitantemente, a nutriz avalia a repercussão da amamentação em sua saúde, o que pode ser percebido como um processo fisiológico harmonioso, mas pode também ser vivenciada com desconfortos, como atividade cansativa, por exigir esforço físico e emocional.

Esses elementos devem ser vistos em consonância com a percepção dos sentimentos, que são gerados a partir do ato de amamentar, que podem resultar na percepção da sensação de prazer ou de contrariedade. Nesse sentido, Silva (1994) e Arantes (1991) afirmam que muitas vezes estes sentimentos são encobertos ou inconfessáveis pela mulher. Influenciam implicitamente o curso da amamentação, mas nem sempre são expressos claramente.

A vergonha de expor as mamas em público e perceber-se observada por estranhos e até mesmo por familiares, em um momento tão íntimo, é considerado por algumas mulheres como uma razão suficiente para oferecer mamadeira quando se vê nessa situação. Assim, as razões pelas quais a mãe desmama são muito complexas e, ao contrário do que se pensa, o índice de mulheres que expressam medo e vergonha de amamentar é muito alto (Silva ,1994).

Os estudos baseados na Representação Social explicitam o conflito feminino entre a idéia de corpo público e corpo privado, espelhando o conceito gerado a partir do Interacionismo Simbólico, que demonstra que a mulher atribui significados ao efeito da amamentação em seu corpo que responde aos efeitos fisiológicos da amamentação e, o corpo que ela entende ser dela e sobre o qual, decidirá, mediante o significado que a amamentação tem para ela.

Por outro lado, esta pode ser uma experiência agradável, dando prazer em amamentar, achando natural e sentindo-se bem em amamentar o que, em primeira instância, é resultado de uma atitude positiva da mãe diante da amamentação, desenvolvida pela observação de outras mães amamentando, ou ainda pela percepção da maternidade envolvendo a afetividade e a crença de que a amamentação favorece a ligação e aproximação entre mãe e filho (Silva ,1994). No estudo de Nakano (1996) mesmo as mulheres que assim representam a amamentação, 
não amamentaram por mais de três meses.

O estudo de Silva (1994) explicita que à medida que a mulher define a situação de amamentar para si ela passa a representá-la em termos simbólicos de riscos e benefícios. Simbolicamente, o risco corresponde às intrerpretações sobre o que a amamentação traz para a mulher ou para a criança, como alguma possibilidade de perda, prejuizo, dano, desvantagem, perigo e ameaça física, emocional ou social. Por outro lado, seguindo o mesmo raciocínio, a amamentação pode significar benefícios colhidos pela mãe ou para a criança, quando interpretada como ganhos, proveitos, vantagens, prazer e satisfação, obtidos no processo de amamentar ou ser amamentado.

A tomada de decisão em relação a amamentar segue uma avaliação das necessidades do recém-nascido e da própria nutriz. Aquilo que for interpretado como prioridade decidirá as ações na condução da amamentação, que visa atender as suas próprias necessidades ou as necessidades de seu filho, pesando o que considera risco ou benefício (Silva ,1994).

A vivência do processo do aleitamento materno, em que a mulher o conduz, pesando riscos e benefícios, encontra seus maiores conflitos no enfrentamento da decisão tomada, pois, muitas vezes, é difícil de ser definida perante os valores sociais impostos (Silva ,1994).

Dessa forma, os riscos apontados como determinantes do curso da amamentação, geralmente, apontados pela literatura como causas mais comuns do desmame, na verdade constituem-se, muitas vezes, na camuflagem para os simbolos reais percebidos pela mãe na sua vivência da amamentação, uma vez que elas tendem a dar respostas socialmente mais convincentes e que não prejudiquem sua auto-estima para justificar o desmame (Silva ,1994).

\section{FINALIZANDO}

Na visão tradicional do amamentar, a mensagem psicanalitica agrega a mãe ao filho, exigindo dela a adoção de uma forma de ser e interagir no seu mundo. A visão de obrigatoriedade, de cumprimento de deveres, calcados nos pressupostos de um papel e função a desempenhar, de um ato instintivo e natural, contribui para a percepção da amamentação como uma tarefa a cumprir e sempre com êxito.

A nova visão, que se constrói da amamentação, se contrapõe a visão tradicional e busca ampliar a compreensão das sutilezas da vivência de amamentar, conjugando os componentes biológicos aos elementos subjetivos da experiência da mulher/mãe como um todo.

As interfaces dos resultados desses estudos demonstram que, longe de ser uma resultante biológica, o amamentar envolve as emoções da mulher que vive um processo interativo com seu filho em seu contexto, revelando as consonâncias e as colisões dessa atividade com os objetivos de vida, necessidades pessoais, sociais, profissionais e econômicas da mulher, calçadas nas representações construidas ao longo de suas vidas em suas comunidades.

O núcleo do processo do amamentar é a mulher. A mulher que vê a amamentação pelos olhos de mãe, julgando beneficios e riscos para o filho, mas também a mulher que enxerga na amamentação riscos e benefícios para si. A mulher que desempenha papéis transitórios em sua vida, como o de gestante, mas desempenha uma somatória de papéis definitivos como o de mãe, esposa, amante, trabalhadora, e acima de tudo o papel de MULHER quer para si ou para a sociedade.

As interfaces dos principais conceitos gerados desses estudos, nos mostram que as experiências da mulher se dão a partir da organização dos papéis atribuídos a ela, mediante atributos de significados individuais, os quais são incorporados de forma integral e completa em um conjunto amplo, em que todas as performances acontecem ao mesmo tempo.

Segundo (Hall, 1992) a organização de papéis ocorre, em primeira instância, com a identificação desses e através de dois processos avaliativos. No caso da nutriz, segundo Silva (1994) ela julga a conveniência dos seus papéis centrais e como eles se ajustam uns aos 
outros; ela interpreta o significado de cada papel assim como as suas combinações à luz das influências de seu contexto, tornando-se apta a planejar e agir a fim de organizar seus desempenhos. Através da observação e percepção, a mulher avalia os aspectos de cada papel e suas conseqüências de acordo com um referencial interno de valores, padrões morais e expectativas pessoais. Considera o valor desses papéis e atribui a eles configurações positivas ou negativas. Caso a intensidade dessa avaliação reflita desapontamento, desconforto, perigo ou sobrepuje os aspectos favoráveis, o papel é avaliado negativamente. Quando os papéis são considerados positivamente, estes refletem prazer, entusiasmo, contentamento e escolha pessoal

Ainda, concomitantemente, ocorre um processo estimativo o qual representa a avaliação dos papéis segundo as conseqüências do desempenho desses de acordo com referenciais externos como social, econômico, e até mesmo contingências políticas.

A realidade contextual é um fator limitante ou facilitador das opções da mulher em como organizar e desempenhar seus papéis no seu cotidiano, influindo assim, nas tomadas de decisão quanto ao amamentar.

As diferentes formas das mulheres representarem a situação de amamentar e os diferentes significados atribuidos aos símbolos identificados em sua experiência, deve-se ao fato da mulher não reagir à amamentação de uma forma puramente instintiva. Suas ações são determinadas por uma visão pessoal da experiência devido a diferenças de possibilidades interpretativas, crenças, valores, originando a variação de reaçōes individuais que se percebe diante do fenômeno da amamentação.

As diferentes formas de percepção e interpretação da experiência de amamentar são únicas para cada mulher. O processo de percebê-la é que se apresenta de uma maneira uniforme, direcionando sua forma de vivenciar não só a amamentação, mas a maternidade (Silva , 1994).

Assim, o profissional, ao colocar-se na situação de assistir à mulher e seu filho no processo da amamentação, deve interagir com ela de forma a compreendê-la, assumindo o seu papel, buscando uma comunicação efetiva para ajudá-la. Compreender que a mulher vivencia um processo interpretativo de sua experiência, avaliativo e estimativo dos simbolos que atribui à vivência de amamentar, é um ponto de inegável importância para o planejamento de ações em relação ao aleitamento materno (Silva, 1998).

É preciso salientar a influência exercida pelos familiares, amigos e profissionais, destacando-se a importância do papel exercido por essas pessoas que convivem de alguma maneira com a nutriz. Infelizmente, diante do despreparo de muitos profissionais, ou das contradiçōes evidenciadas no meio familiar, esses mesmos "mecanismos de apoio" do contexto, onde a experiência se dá, podem exercer uma interferência negativa sobre a mulher, podendo confundi-la, oprimi-la ou tornar o amamentar uma situação difícil de ser vivenciada (Silva,1999).

Nesse sentido, estudos retratam a visivel influência dos profissionais junto à nutriz. $A$ atuação desses profissionais é vista pela mulher de uma forma policialesca e autoritária, em que a relação não se estabelece de forma franca. Para a mulher o profissional simboliza a censura quando esta não amamenta ou o dever cumprido, quando consegue manter a amamentação.

Penso que, o evoluir do papel da mulher na sociedade, não tem sido acompanhado pelas idealizações sobre o papel de mãe e provedora do cuidado ao recém-nascido, calcado em uma visão reducionista de mulher/reprodutora, submetida às leis da natureza. Isto explica o modelo atual que orienta as açōes de incentivo ao aleitamento, ignorando a vivência da mulher e sua autonomia no curso da amamentação.

A amamentação, sob o prisma do ato social que representa, é vista como de exclusiva e absoluta responsabilidade da mulher, e esta tem ancorado nos determinantes biológico e técnico as respostas aos seus fracassos. Segundo essa ótica, não há lugar para os sentimentos e percepções maternas como determinantes do processo, o que leva a mulher a utilizar-se de 
justificativas que a isentem da responsabilidade de não conseguir amamentar (Silva,1994).

Os conceitos teóricos, gerados pelos estudos aqui citados, compõem as interfaces da aproximação da realidade vivenciada pela mulher na sua experiência de amamentar.

Embora esses estudos tenham sido desenvolvidos através de diversas abordagens da pesquisa qualitativa, eles apresentam um denominador comum quanto ao fato de evidenciarem a necessidade de se considerar a amamentação como uma experiência contida na vivência da maternidade e não a maternidade em si.

Se um novo olhar é lançado sobre a prática da amamentação, é necessário acompanhálo e pensar, planejar e redimensionar uma assistência que o considere como o fenômeno social que este representa na vivência da mulher, da criança e da familia, considerando a singularidade desse processo.

ABSTRACT: The purpose of this study is to understand the issues related to breastfeeding, which have generated the current scene, as well as, new scientific trends in this area. It also indicates current concepts, which emerged from qualitative studies done by nurses having as reference different theoretical models. These studies show that breastfeeding depends on the meanings women attribute to this experience built through their personal history and interactions within the family and community context. In general, their studies elucidate the experience of breastfeeding and provide tools for nursing professionals to develop in their practice with the mother, infant and family during the breastfeeding period.

KEYWORDS: qualitative research, breastfeeding, health care model

RESUMEN: Para comprender el escenario de los temas relacionados con la práctica de la amamantación, que han suscitado el cuadro actual y las tendencias de la producción científica en esa área, el presente trabajo comenta los principales conceptos surgidos de estudios calitativos realizados por enfermeras, a partir de diferentes perspectivas teóricas. Dichos estudios muestran que el proceso de amamantar depende de los significados atribuidos por la mujer a la experiencia de amamantar y que se fueron construyendo durante sus historias de vida y las interacciones actuales en su ambiente familiar y comunitario. En su conjunto, los trabajos dilucidan la experiencia de amamantar y ofrecen elementos para que los profesionales elaboren su práctica en la asistencia a la mujer, al lactante y a la familia, en esa fase.

PALABRAS CLAVE: investigación calitativa, amamantación, modelo asistencial

\section{REFERÊNCIAS BIBLIOGRÁFICAS}

ARANTES, C.I.S. O fenômeno amamentação: uma proposta compreensiva. Ribeirão Preto, 1991. 86p. Dissertação (Mestrado) - Escola de Enfermagem de Ribeiräo Preto, Universidade de Säo Paulo.

ARAÚJO, L.D.S. Querer/poder amamentar. uma questão de representação? Florianópolis, 1991. 104p. Dissertação (Mestrado) - Departamento de Enfermagem, Universidade Federal de Santa Catarina.

COSTA, J.F. Ordem médica e norma familiar. Rio de Janeiro: Graal, 1989. 
DONZELOT, J. A polícia da familias. 2.ed Rio de Janeiro: Graal, 1986.

FARGE, A.;DAVIS, N.Z. Ela, de quem tanto se falou. In: DUBY,G. PERROT,M. História das mulheres no ocidente. Do renascimento à Idade Moderna. Porto: Afrontamento, 1991. v. 3, p.295- 455.

HALL, J.M. Developing the construct of role integration: a narrative of women clerical worker's daily lives. Res. Nurs. Health, v.15, n.6, p.447-57, 1992.

MOTA,J.A.C. Ideologia implicita no discurso da amamentação materna e estudo retrospectivo comparando crescimento e morbidade de lactentes em uso de leite humano e leite de vaca. Belo Horizonte, 1990.226p. Tese (Doutorado) - Faculdade de Medicina, Universidade Federal de Minas Gerais.

NAKANO, A.M.S. O aleitamento materno no cotidiano feminino. Ribeirão Preto. 1996. 170p. Tese (Doutorado) - Escola de Enfermagem de Ribeirăo Preto, Universidade de São Paulo.

SILVA, I. A. Amamentar. uma questão de assumir riscos ou garantir beneficios. São Paulo. 1994. 198p. Tese (Doutorado) - Escola de Enfermagem, Universidade de Säo Paulo.

SILVA, I. A. Abordagem da mulher na conquista da amamentação. ENCONTRO PAULISTA DE ALEITAMENTO MATERNO, 9., São Paulo, 1998, Anais... São Paulo, UNIFESP, Departamento de Enfermagem, 1998. p.39-43p.

SILVA, I.A. Construindo perspectivas para a assistência em amamentação: um processo interacional., São Paulo, 1999. Tese (Livre Docência) Escola de Enfermagem, Universidade de Săo Paulo.

SOUZA,I.E.O. O desvelar do ser gestante diante da possibilidade de amamentação. Rio de Janeiro, 1993.103.p. Tese (Doutorado)- Escola de Enfermagem Anna Nery, Universidade Federal do Rio de Janeiro.

Recebido em maio de 2000

Aprovado em novembro de 2000 